\title{
Understanding Preservice Mathematics Teachers' Technology Use: Some Pedagogical Issues
}

\author{
Hatice Akkoç ${ }^{1}$, Hande Gülbağcı Dede ${ }^{2}$ \\ ${ }^{I}$ Marmara University, Istanbul,Turkey,hakkoc@marmara.edu.tr \\ ${ }^{2}$ Marmara University, Istanbul, Turkey, hande.gulbagci@marmara.edu.tr
}

\begin{abstract}
Becoming technology literate citizens has gained great importance in recent decades. Technology also has become crucial for the teaching and learning of school subjects as well as the workplace. For successful technology integration, teachers should have adequate pedagogical and technological knowledge, beliefs and attitudes. The aim of this study is to explore how PMTs describe characteristics of a good teacher who integrates technology into instruction, what they would consider when they teach with technology and what kinds of problems they anticipate in their future classrooms. The participants are twenty senior pre-service mathematics teachers enrolled in a four-year teacher preparation program in a state university in Turkey. The study used an online form to collect data. We analyzed participants' written responses using the technological pedagogical content knowledge (TPCK) framework. Findings indicated that participants considered issues such as technical knowledge and skills, content knowledge, the pedagogy of using technology, the interrelation between content to be taught and software, and time constraint. With regard to students, participants anticipate problems such as negative attitudes towards mathematics, mathematical misconceptions that might emerge as a result of inappropriate use of technology, distraction and time constraint. The paper will propose recommendations for teacher education programs.
\end{abstract}

KEYWORDS: preservice mathematics teachers, technology integration, preservice teacher preparation, technological pedagogical content knowledge (TPCK)

\section{Introduction}

Technology is an important part of our daily life. Today's citizens need to work and learn with technology. Advancements in digital technology also affected educational technologies. Among the school subjects, mathematics has a special place in instructional technologies. Many mathematics curriculum documents around the world emphasize that technological tools should be an integral part of mathematics teaching (NCTM, 1989, 2000; DfES, 2013a, 2013b). Many studies indicate that technological tools promote conceptual learning in the context of mathematics (Noss \& Hoyles, 1996; Knuth \& Hartmann, 2005; Habre \& Abboud, 2006).

For successful technology integration, teachers should have adequate pedagogical and technological knowledge, beliefs and attitudes. Knowledge required for effective use of technology is defined as Technological Pedagogical Content Knowledge (TPCK) first by Pierson (1999) and Niess (2005). It is based on Shulman's $(1986,1987)$ notion of pedagogical content knowledge (PCK) which described the teacher's knowledge as the interaction of pedagogical knowledge and content knowledge. It is what distinguishes a teacher from an expert. Pierson (1999) and Niess (2005) integrated the technology component to define the knowledge required for successful technology integration (See Figure 1). 


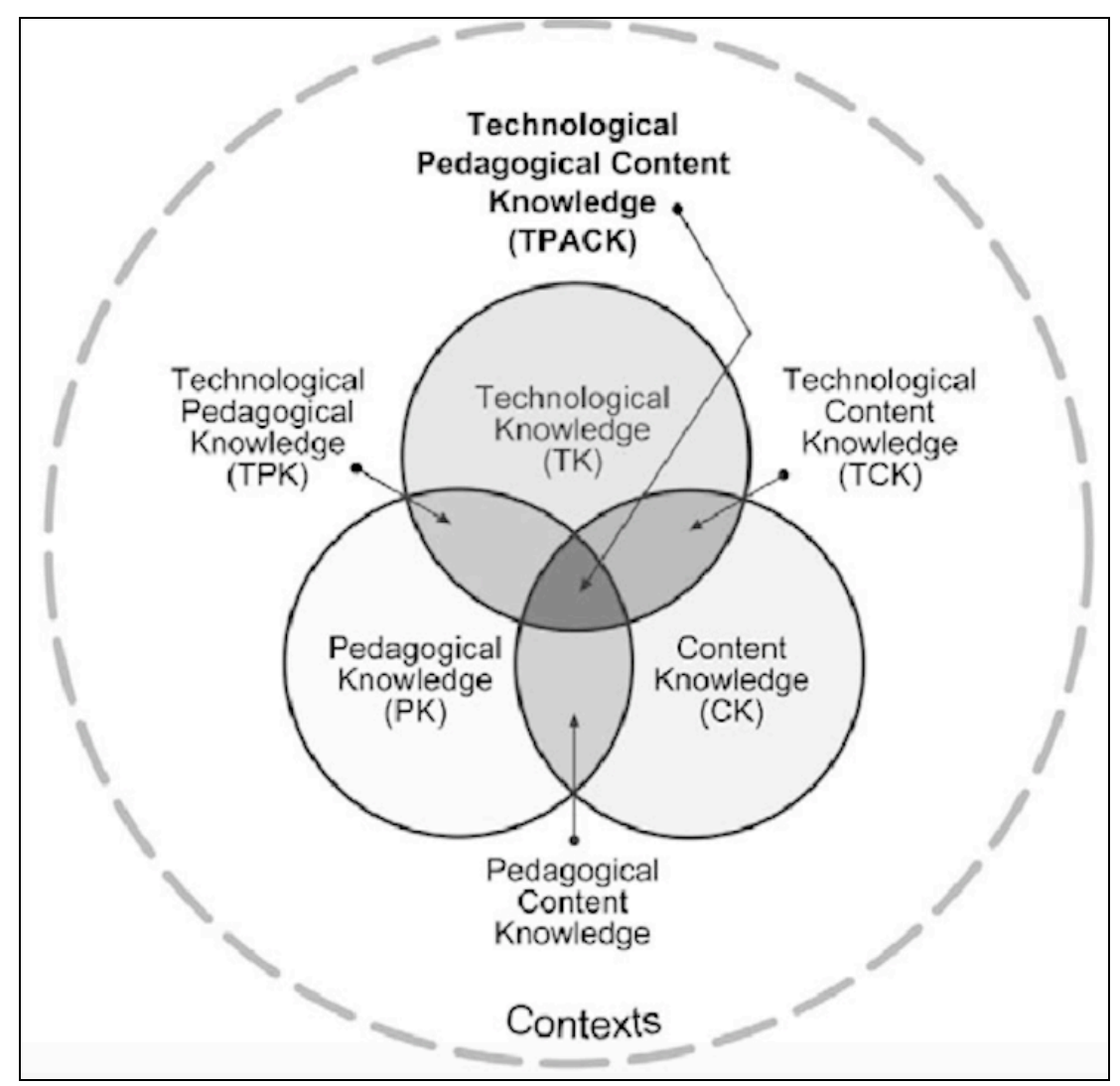

Figure 1. Components of Technological Pedagogical Content Knowledge (C) 2012 tpack.org)

Mishra and Koehler (2006) define each category and intersections of categories. Content knowledge $(\mathrm{CK})$ is concerned with the topic to be taught e.g. knowledge of fractions. Pedagogical knowledge (PK) is the knowledge of classroom management, instructional principles etc. Technical knowledge (TK) includes knowledge and skills for using technological resources. Having the knowledge and related skills represented by these three distinct knowledge categories is not enough to successfully teach with technology. Teachers also should have knowledge regarding the intersections of these knowledge categories. Pedagogical content knowledge (PCK) is the knowledge of instructional strategies for teaching a particular topic e.g. structure and teaching strategies for teaching fractions. Technological content knowledge (TCK) is concerned with knowing different ways to represent the content using different technological tools e.g. affordances and constraints of different software to represent fractions. Technological pedagogical knowledge is related to general pedagogical issues that raise in technology-enhanced lessons e.g. knowledge and skills for classroom management that can change with the existence of technology in the classroom. TPCK "is an emergent form of knowledge that goes beyond all three components" (p. 1028).

The aim of this study is to explore how well prepared the preservice mathematics teachers are to teach with technology with appropriate pedagogy. For this aim, we will use the TPCK framework as a tool for data analysis.

\section{Methodology}

This paper reports on a descriptive study that sets out to investigate how well-prepared preservice mathematics teachers are to teach with technology with appropriate pedagogy. The participants are twenty senior pre-service mathematics teachers (PMTs) (15 female, 5 male) enrolled in a four-year teacher preparation program in a state university in Turkey. PMTs took mathematics education courses such as mathematics, geometry, and algebra teaching methods courses. Technology-related courses PMTs took are Information and Communication Technologies in Mathematics Education I and II.

The study used an online questionnaire to collect data. The aim of this form is to find out different ways of using technology among participants. PMTs filled the questionnaire before they 
took Mathematics Instructional Technologies and Material Design course. In the context of this study, we focused on the following three questions:

(a) What are the features that a mathematics teacher should have to teach a technologysupported lesson?

(b) What would you consider when incorporating technology into your lessons if you were working in a school with technological equipment?

(c) What kinds of problems of using technology do you anticipate for your future students?

We used content analysis to analyze the answers to the above questions. Two themes emerged from the analysis of the answers to the first question: teachers' knowledge and personal characteristics. We used the TPCK framework to categorize the first theme. Open coding was used to analyze the second theme. We also used TPCK categories to analyze the answers to the second question. Again, we used open coding to analyze the answers to the third question.

\section{Findings}

This section will present the findings regarding each question in the questionnaire. features that a mathematics teacher should have to teach a technology-supported lesson. Table 1 presents the categories of features that a mathematics teacher should have to teach a technology-supported lesson.

Table 1. Categories of characteristics that a mathematics teacher should have to teach technologysupported lessons

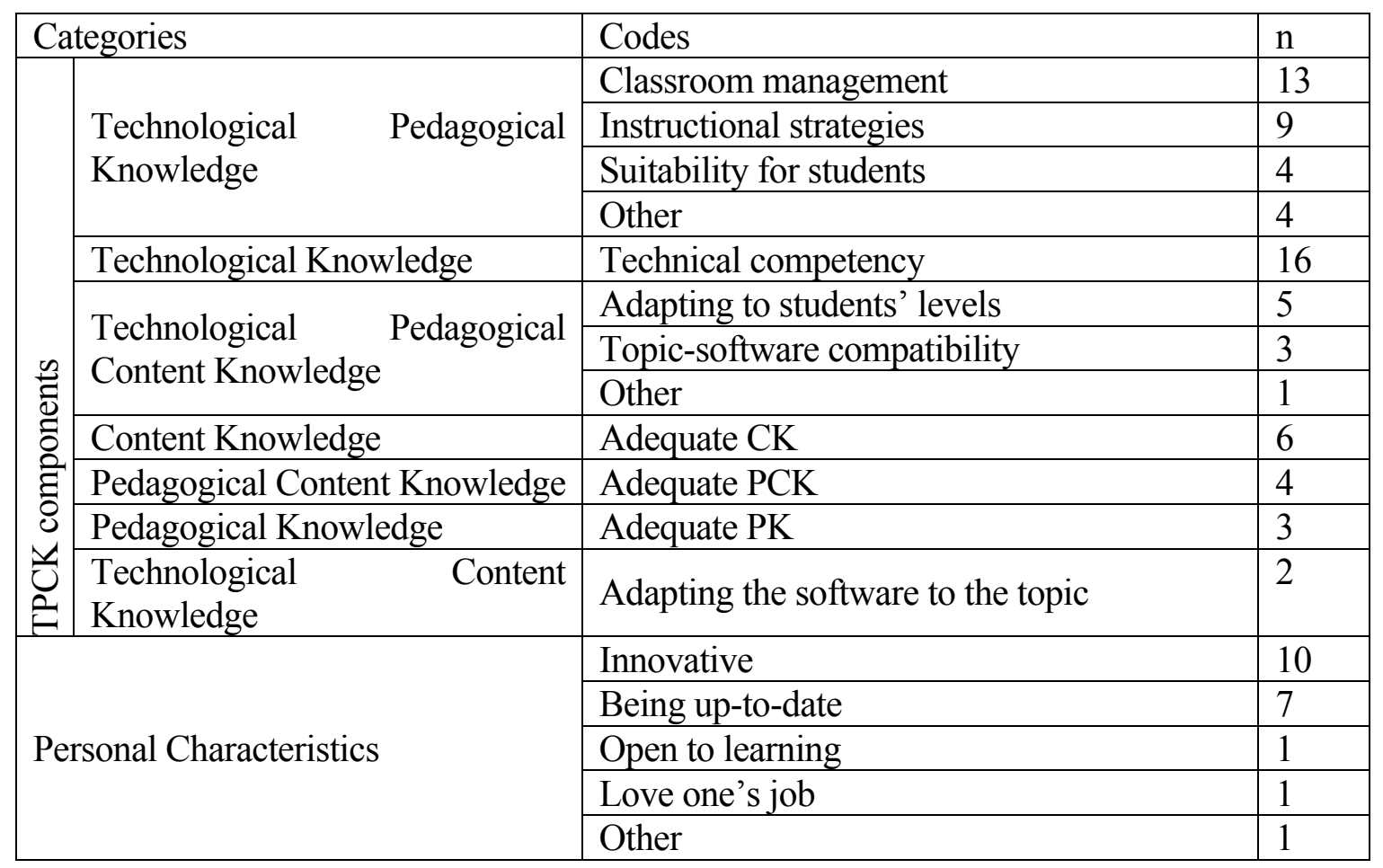

In Table 1, note that since each participant might have noted down more than one answers, the total number of frequencies for all categories is greater than the number of participants. As can be seen in Table 1, teacher knowledge $(n=70)$, rather than personal characteristics $(n=20)$, came to the forefront. In the category of teacher knowledge, the frequency for technological pedagogical knowledge (TPK) is 30 . Within TPK, classroom management $(n=13)$, instructional strategies $(n=9)$ and adapting technology to students in a technology-enhanced lesson $(n=4)$ are the sub-categories. One of the participants mentioned the following with regard to classroom management:

Since we use a different tool in the classroom, control of the classroom and the lesson become more important. Both inspiring interest and keep the students' attention and adhering to the content to be taught. These are very important. (PMT2) 
The teacher's classroom management should be good. Since it's gonna be online, you have to make sure that students use the computer for the aim of the lesson. (PMT10)

Another sub-category of TPK is related to instructional strategies. Participants mentioned about different strategies such as asking the right questions, ensuring participation and finding daily-life examples.

The second most frequent category is technical knowledge (TK). 16 answers were related to the technical competence of teachers.

The teacher should a grasp of the technological tool that she would choose. Because of

time management issues. It would be better if teachers wait until they will be competent

with the software they just discovered. (PMT4)

Another category is technological pedagogical content knowledge in which technical, pedagogical and content knowledge interact with each other. Within this component, various subcategories emerged (See Table 1). They mentioned that teachers should make the content comprehensible to students with technological tools $(\mathrm{n}=5)$ and present the mathematical content with the most suitable software $(\mathrm{n}=3)$ :

When relating the content and software, you have to consider the level of students to promote learning. For example, there are a lot of resources for GeoGebra. When presenting them, you have to choose the ones that are suitable for the math curriculum. (PMT13)

The teacher has to discover which software is suitable to make the content comprehensible for students beforehand. (PMT1)

Another participant mentioned that the teacher has to have adequate content knowledge since the compatibility of content and technology is effective for student learning and understanding. These explanations reflect the interplay between technology, content, and pedagogy.

As can be seen in Table 1, participants also referred to other categories such as content knowledge $(n=6)$, pedagogical content knowledge $(n=4)$ and pedagogical knowledge $(n=3)$ with lower frequencies.

When it comes to personal characteristics, sub-themes such as innovation, being up-to-date become prominent which are exemplified with the excerpts below:

A teacher who teaches with technology should be open to innovations and must investigate.

Because a teacher should follow and use technologies which change quite rapidly. (PMT2)

The teacher should follow the advancements in technology closely, be open to innovation and not be narrow-minded...to give a simple example, I submitted some of my coursework via online classroom. I did not have to submit the paperwork. The teacher must be competent with this kind of applications which make life easier. (PMT14)

As can be seen from the excerpts above, PMT2 and PMT14 point out to personal characteristics (e.g. being innovative) rather than articulating the types of knowledge required to achieve this innovation.

Another question in the online questionnaire was related to what would PMTs consider when incorporating technology into their lessons if they were working in a school with technological equipment. Categories emerged are presented in Table 2 below.

As can be seen in Table 2, PMTs' answers are mostly related to technological pedagogical knowledge $(n=22)$. In other words, they tend to take pedagogy of technology when teaching a lesson. Within this component, they mentioned that they would ensure students' active participation $(n=8)$, look for the suitability of technology for students' levels $(n=7)$ and use the time efficiently since the time-management is an important issue in technology-enhanced lessons $(n=4)$. PMT8 who mentioned about students' active participation, emphasized the importance of students' active use of technology rather than using technology as a demonstration tool. Another participant PMT7 wrote the importance of taking students' levels of technology use into account.

Within the technological pedagogical content knowledge category, one of the sub-theme was related to the compatibility of content and software $(n=6)$. PMT1 wrote the following: 
I would be careful about the compatibility of content and software. I don't think every topic can be taught using every software. I think GeoGebra is more suitable than Graphic Calculus to teach the concept of slope because it's more visual and easier to use. In sum, I would consider the content of the software. (PMT1)

Table 2. The findings of what PMTs consider when using technology in lessons

\begin{tabular}{|c|c|c|c|}
\hline \multicolumn{2}{|c|}{ Categories } & Codes & $\mathrm{n}$ \\
\hline \multirow{8}{*}{ 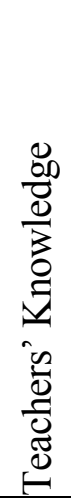 } & \multirow{4}{*}{$\begin{array}{l}\text { Technological } \\
\text { Knowledge }\end{array}$} & Student cantered-active participation & 8 \\
\hline & & Suitability for students & 7 \\
\hline & & Timing & 4 \\
\hline & & Other & 3 \\
\hline & $\begin{array}{l}\text { Technological Pedagogical Content } \\
\text { Knowledge }\end{array}$ & Compatibility of content and software & 6 \\
\hline & Technological Knowledge & Grasp of technology & 3 \\
\hline & $\begin{array}{ll}\text { Technological } & \text { Pedagogical } \\
\text { Knowledge } & \\
\end{array}$ & Classroom management & 2 \\
\hline & \multicolumn{2}{|l|}{ Other } & 5 \\
\hline
\end{tabular}

As can be seen from the excerpt above, PMT1 compares two software based on what each software could do. The other two categories are classroom management which is related to TPK and grasp of technology which is related to TK.

The third question in the questionnaire was related to the kinds of problems with using technology that PMTs anticipate for their future students. Table 3 presents codes emerged from the data analysis of responses.

Table 3. Anticipated problems with using technology

\begin{tabular}{|l|l|}
\hline Codes & $\mathrm{n}$ \\
\hline Students' lack of interest in technology & 7 \\
\hline Limited access to technology & 7 \\
\hline Possible problems & 5 \\
\hline Problems with students' understanding & 3 \\
\hline Negative attitudes towards mathematics & 2 \\
\hline Crowded classrooms & 2 \\
\hline Time constraint & 2 \\
\hline Technical problems & 1 \\
\hline Other & 2 \\
\hline
\end{tabular}

As can be seen in Table 3, the most frequent codes were students' lack of interest in technology and limited access to technology. Interestingly, seven PMTs taught students would not be interested in using technology. One of them mentioned that students might think that technology would make the lesson harder.

\section{Conclusion}

This study explored how well prepared the preservice mathematics teachers are to teach with technology with appropriate pedagogy through a descriptive study. We used the technological pedagogical content knowledge (TPCK) framework to describe how PMTs describe characteristics of a 
good teacher who integrates technology into instruction, what they would consider when they teach with technology and what kinds of problems they anticipate in their future classrooms.

Although participants just started the Instructional Technologies and Material Design course and did not start the module which focuses on the pedagogy of using technology, they surprisingly referred to various components of TPCK. Findings indicated that participants considered issues such as technical knowledge and skills, content knowledge, the pedagogy of using technology, the interrelation between content to be taught and software, and time constraint. With regard to students, participants anticipate problems such as negative attitudes towards mathematics, mathematical misconceptions that might emerge as a result of inappropriate use of technology, distraction and time constraint.

Considering the findings, we propose recommendations for teacher education programs. First, the study indicated that the TPCK framework was useful to explore how PMTs describe important aspects of using technology in mathematics lessons. Second, we recommend teacher educators should take pre-service teachers' preconceptions into account before they take courses on the pedagogy of using technology. Revisiting their preconceptions during such courses would help them articulate their ideas about effective ways to teach with technology.

\section{Acknowledgments}

This study is part of a research project (project number EGT-A-150218-0081) funded by Marmara University Scientific Research Projects Commission.

\section{References}

Department for Education and Skills (DfES). 2013a. National Curriculum in England: Mathematics Programmes of Study - Key Stages 1 and 2 (No. DFE-00180-2013). London: DfES.

Department for Education and Skills (DfES). 2013b. National Curriculum in England: Mathematics Programme of Study - Key Stage 3 (No. DFE-00179-2013). London: DfES.

Habre, Samer, and Abboud, May. 2006. "Student's Conceptual Understanding of a Function and Its Derivative in an Experimental Calculus Course." The Journal of Mathematical Behavior 25: 57-72.

Knuth, E., and Hartman, C. E. 2005. "Using Technology to Foster Students' Mathematical Understandings and Intuitions.” In Technology-Supported Mathematics Learning Environments: Sixty-Seventh Yearbook, edited by W. J. Masalaski, 151-164. Reston, VA: National Council of Teachers of Mathematics.

Mishra, Punya, and Koehler, Matthew J. 2006. "Technological Pedagogical Content Knowledge: A framework for Teacher Knowledge.” Teachers College Record 108(6):1017-1054.

National Council of Teachers of Mathematics (NCTM). 1989. Curriculum and Evaluation Standards for School Mathematics. Reston, VA: National Council of Teachers of Mathematics.

National Council of Teachers of Mathematics (NCTM). 2000. Principle and Standards for School Mathematics. Reston, VA: National Council of Teachers of Mathematics.

Niess, Margaret L. 2005. "Preparing Teachers to Teach Science and Mathematics with Technology: Developing a Technology Pedagogical Content Knowledge." Teaching and Teacher Education 21(5): 509-523.

Noss, Richard, and Hoyles, Celia. 1996. Windows on Mathematical Meaning: Learning Cultures and Computers. Dordrecht, The Netherlands: Kluwer.

Pierson, M. E. 1999. “Technology Integration Practice as a Function of Pedagogical Expertise.” PhD diss., Arizona State University.

Shulman, Lee S. 1986. “Those Who Understand: Knowledge Growth in Teaching.” Educational Researcher 15(2):4-14.

Shulman, Lee S. 1987. "Knowledge and Teaching: Foundations of the New Reform." Harvard Educational Review 57(1):1-23. 